\title{
New Improvement of Labor Accounting in the Sharing Economy
}

\author{
Yuanxiang Zhou $^{1}$ and Weichuan Yin $\mathbb{D}^{2}$ \\ ${ }^{1}$ Institute of Statistics and Applied Mathematics, Anhui University of Finance and Economics, Bengbu 233030, China \\ ${ }^{2}$ One Belt-One Road Strategy Institute, Tsinghua University, Beijing 100084, China
}

Correspondence should be addressed to Weichuan Yin; yinweichuan@mail.tsinghua.edu.cn

Received 16 September 2019; Accepted 6 January 2020; Published 13 January 2020

Academic Editor: Soheil Salahshour

Copyright (c) 2020 Yuanxiang Zhou and Weichuan Yin. This is an open access article distributed under the Creative Commons Attribution License, which permits unrestricted use, distribution, and reproduction in any medium, provided the original work is properly cited.

\begin{abstract}
The investigation of labor is a key aspect of population research, and labor accounting, as its foundation, is an important means to judge the degree of economic development and monitor the changes of the labor market, having always been a focus of scholarly research. At present, the sharing economy is on the rise worldwide and influences labor accounting. In this paper, starting from the context of the sharing economy and the current situation of labor accounting, several important aspects of labor accounting will be discussed. In the context of the sharing economy, household subsistence service production is to be included in the production accounting boundary, which is the root of the changes in labor accounting. On this basis, the following findings are drawn. (1) The scope of accounting for employment should be expanded, which puts higher demands on the labor accounting method. (2) Working time should be remeasured, especially indicators based on pay time. (3) Finally, the design of indicators in labor underutilization also requires the formation of new ideas, especially unemployment should be redefined. Finally, in view of the current status of labor accounting in China, policy suggestions for future improvement under the sharing economy are put forward.
\end{abstract}

\section{Introduction}

Currently, the sharing economy has become the new trend in global economic development, the breadth and depth of its impact having greatly exceeded expectations and significantly influenced traditional economic and industrial models. Concurrently, it has profoundly affected people's production and lifestyle models and has put forward a new topic on how government departments can improve economic and social management.

Since Weitzman [1] systematically proposed the theoretical framework of sharing economy, the improvement of the sharing economy and the opportunities and challenges it brings have received increasing attention from the academic community [2-5]. On the one hand, in terms of the new changes in the sharing economy, Allen [6] believes that it has formed a new model of multiplatform trading, while Zervas et al. [7] point out that the sharing economy optimizes industrial resources and drives the development of the industry, which creates the possibility for trading the idle resources of most societies, thus resulting in more new deals. In addi- tion, Rogers [8] believes that, under the sharing economy, an effective market can accelerate self-formation, and the intrinsic goal of determining the market by supply and demand can be realized more quickly. On the other hand, from the new features embodied in the sharing economy, it reduces the production costs of producers and the search costs of consumers, resulting in a significant reduction in transaction costs [8], while reinforcing the fact that ownership and use rights are separated $[9,10]$, thus achieving collaborative consumption. In recent years, due to national policy guidance and support, the sharing economy has been able to flourish in China. Li and Lv [11] elaborate on the possible future developments of the sharing economy from nine perspectives, including sharing subjects, ideas, scale, scope, and content. Liu and Xia [12] systematically summarize three theoretical analysis frameworks for understanding the sharing economy, namely, transaction cost, collaborative consumption, and multilateral platform theories, and specifically discuss its connotations and impact.

From the above research status of the sharing economy both in China and abroad, the discussion on its new features, 
new content, and improvement prospects is extensive, with some scholars having verified the practical effect of sharing economy at different levels $[13,14]$; most of their research is based on the sharing economy program, which includes the Employee Stock Ownership Plan (ESOP), Stock Option Plan (SOP), and Limited Partnership (LP). However, with the improvement of the sharing economy, sharing accounting data need to be collected in a more timely and extensive manner and the impact evaluation of the sharing economy also needs to be supported by systematic statistical accounting methods.

At present, the System of National Accounts (SNA) is the most authoritative standard of international accounting that fully outlines and reflects the functioning of the national economy and provides guidance for economic development [15]. On the one hand, traditional national accounts have been unable to account for the improvement of the sharing economy, the necessary decision-making information lacking in the formulation of sharing economy improvement policies. On the other hand, the sharing economy has also changed the connotations of traditional economic statistical indicators to a great extent, and if its development cannot be reflected in the practice of national economic accounting in a timely manner, its significant economic and social impact cannot be adequately derived, which will affect the scientific nature of national economic policies.

In this paper, labor accounting, one of the main components of national economic accounting, is analyzed and the impact of the sharing economy on it is elaborated. Labor accounting is an important aspect of national economic accounting. Historically, in 1919, the International Labor Organization (ILO) was established by the United Nations as a specialized agency to provide a systematic management basis for labor accounting and still plays a key role in setting statistical standards for labor accounting, establishing an indicators system related to labor, and resolving international labor problems. Over time, the specific concepts, definitions, classifications, and other contents of labor accounting have been proposed by the International Conference of Labor Statisticians (ICLS), its resulting resolutions and guidelines being approved by the Governing Council of the International Labor Organization and forming the final standard of accounting for labor statistics. The first meeting of the ICLS was officially held in 1923 and hitherto 19 meetings have taken place, covering various aspects of employment and unemployment statistics, labor time division, and classification of work types, among others, to address the problems arising from labor accounting and provide a standardized approach for international comparisons.

Labor accounting is not only an important means for a country to monitor changes in its labor market but also the basis for international labor comparisons. Many scholars have conducted extensive research based on labor accounting data. For example, Cai et al. [16] examine the changes in China's labor market from the perspectives of laid-off and registered unemployment, unemployment rate, and labor participation rate, clarifying long-standing issues in China's employment statistics. He considers that, in the context of the rapid development and dramatic transformation of
China's economy, China's employment statistics have an inherent consistency. At the same time, Cai [17] analyzes the reverse change relationship between China's economic growth and explicit employment using labor accounting data and proposes that the labor market mechanism should be improved and the development of high-employment industries promoted. The relationship between economic growth and employment has long been a topic of concern for Chinese scholars [18, 19]. Similarly, research using labor accounting data has focused on a broader range of aspects, such as labor cost and quality [20-29].

In sum, the importance of labor accounting is obvious. In the context of the sharing economy, its accounting philosophy will change as will some of its content. It is worth emphasizing that this paper is not a research of methodology, not a lot of conceptual approaches and mathematical models, but rather a study of the challenges that the relevant concepts of labor accounting may encounter under the new economic development, and whether the relevant indicators need to be redefined and adjusted, but these purely literal expressions are crucial because it is the most important foundation of methodology research. However, there are few systematic discussions on related topics. Consequently, the following sections discuss in detail the impact of sharing economy on the main aspects of labor accounting, to provide guidance on how the existing accounting should face the changes in the economic environment and reasonable recommendations for the future directions of labor accounting.

\section{Causes of Changes in Labor Accounting: Production Boundaries}

Under the SNA, production is the starting point for everything and accounting for other accounts must be carried out on the basis of production accounts. Therefore, the understanding of production-related concepts, production accounting processes, and especially the grasp of production boundaries are of great importance. These fundamentally affect all aspects of national economic accounting. Under the sharing economy, the contents of labor accounting will change as the production boundary changes. Consequently, it is necessary to review the production and accounting boundary stipulated in the SNA and to explore the impact of the sharing economy on them.

2.1. Production under SNA. The SNA defines production as the activity of producing goods and services using labor, capital, goods, and services inputs under the responsibility, control, and management of the institutional unit, while the production accounts reflect the output and inputs of production activities (see SNA 2008, 6.2). Among them, the production boundary is a concept particularly emphasized in the SNA. In the economic analysis of production, the main focus is on production activities whose output can be delivered or provided to other institutions, including mainly goods and services (including knowledge carrier products; see SNA $2008,6.13)$. Goods refer to tangible production results that can be identified as transferable ownership (see SNA 2008, 
5.17), while services refer to the results of production activities that can change the status of consumer units or promote the exchange of products or financial assets (see SNA 2008, 6.27); however, both are collectively referred to as outputs or products.

In fact, SNA's general definition of production emphasizes only two points. The first is that the production process must be responsible for the organization unit, and the second is that input factors and output types need to be specified. However, SNA's restrictions on the production boundary are more stringent than the general production boundary it defines, and access to the production boundary described in the SNA requires not only meeting the definition requirements of the general production boundary but also ensuring that they have market characteristics (i.e., all goods and services that may enter the market in the future) as does the output.

For the production of goods, it is easy to determine whether they are in the production boundary of the SNA, while for services, which are also outputs, this issue is not clearly identified in practice, the main reason being that the production of the household sector has characteristics of self-sufficiency. As noted in the SNA, the production of services by household members for their own final consumption is not included in the production scope of national accounts (see SNA 2008, 6.28), such as the preparation and provision of meals, care and upbringing of children, and care of the sick and elderly.

In most countries, a considerable amount of labor is used to produce these services, and improvements in economic welfare are largely due to the consumption of these services. However, the purpose of national accounts is not only to obtain welfare indicators. For unpaid household or personal services produced and consumed within households, their value is not included in the accounting system. The SNA gives the following reasons:

(1) The impact of the production of subsistence services on other sectors of the economy is limited, and the production of services means the ultimate destination of services is consumption. Unlike the production of goods, the goods can be determined after production whether to sell or remain for their own use, and self-sufficiency services have been identified for their own use prior to production

(2) Since subsistence services are not productive activities on the market, they cannot enter the accounting process without a reasonable estimate of appropriate market price

(3) The production decision of subsistence services is affected by neither economic policies nor the formulation of economic policies (except for virtual rent of owner-occupied housing) because the money flow generated for its virtual value and real transactions cannot be equated

As mentioned above, the SNA only incorporates all production activities with market characteristics into its produc- tion accounting scope. The production boundary is clearly defined in the SNA and consists of the following five components:

(1) Production boundary which is production of all goods or services provided or prepared by producers for provision to other units

(2) Subsistence production of all goods retained by producers for their own final consumption or capital formation

(3) Subsistence production of knowledge carrier products retained by producers for their own final consumption or capital formation

(4) Production of subsistence household services for owner-occupiers

(5) Production of family and personal services for the employment of paid domestic workers

As such, the SNA encompasses the production of all goods (whether self-sufficient or delivered to others), all nonsubsistence services, and subsistence production of knowledge carrier products with cargo characteristics, excluding all subsistence service production other than the latter two.

\subsection{Production Boundary under the Sharing Economy. Under} the sharing economy, the production accounting of the SNA excludes most subsistence services in the household sector, the three reasons for it being reviewed here.

First, the SNA considers subsistence service production in the household sector a self-sufficient activity that has a limited impact on other institutional sectors of the economy. Under the sharing economy, production of services in the household sector is not only intended to fully meet its own needs but will also be targeted to any institutional sector. The sharing economy weakens the meaning boundaries of self-sufficiency and non-self-sufficiency, and sharing services in exchange for reporting are bound to have an impact on other institutional sectors. In addition, the SNA emphasizes that, since the production and consumption of subsistence services are carried out simultaneously and there is no possibility of deciding whether they will enter the market after production, it allows subsistence services to enter the accounting process.

Second, the SNA considers that the majority of household services are not produced for the market and thus do not have a basis for establishing their market prices, which makes it difficult to quantify their value in the accounting system and incorporate them into the accounting process. However, under the sharing economy, online transactions based on Internet platforms and Internet of Things (IoT) technologies not only make it easier for household services to be integrated into the market trading process but also provide more convenient and timely access to the price and value information generated by service-sharing transactions. Therefore, the price and valuation of subsistence services is simple under the sharing economy. 
TABLE 1: Correspondence between forms of labor and SNA 2008.

\begin{tabular}{|c|c|c|c|c|c|c|c|}
\hline \multirow[t]{2}{*}{ Production } & \multicolumn{2}{|c|}{ Personal use } & \multicolumn{5}{|c|}{ Used by others } \\
\hline & \multicolumn{3}{|c|}{ Products } & \multirow{3}{*}{ Unpaid internship } & \multirow{3}{*}{ Others } & \multicolumn{2}{|c|}{ Volunteer labor } \\
\hline \multirow[t]{2}{*}{ Labor form } & \multirow[t]{2}{*}{ Services } & \multirow[t]{2}{*}{ Goods } & \multirow[t]{2}{*}{ Employment form } & & & \multirow{2}{*}{$\begin{array}{c}\text { Market and } \\
\text { nonmarket units }\end{array}$} & $\begin{array}{l}\text { Household } \\
\text { production }\end{array}$ \\
\hline & & & & & & & Services \\
\hline
\end{tabular}

SNA 2008

SNA production boundary

SNA general production boundary

(1) Labor for the production of self-use products, that is, the labor of the production of goods or services for their own use. (2) Labor in the form of employment, that is, labor that pays or profits for others. (3) Labor for unpaid internships, that is, labor that obtains work experience or skills for others but does not pay. (4) Volunteer labor, that is, temporary unpaid paid labor. (5) Others: types of community service, labor of prison inmates, etc.

Finally, similar to the reasons for the inclusion of owneroccupied housing services in the production boundary, the SNA considers that there exists a large gap between the rates of owner-occupied and rented housing in different countries and that the value of housing services needs to be fictitious; otherwise, international and crossperiod comparisons of the production and consumption of housing services will be inaccurate. Due to the second reason above, subsistence service production under the sharing economy will produce real currency flows. With the strengthening of the status of selfsufficiency services under the sharing economy, it is bound to establish a two-way relationship with economic policy. Then, the production decisions for self-sufficient services will not only be affected by economic policy but will also affect the formulation of economic policy, thus strengthening the relationship between the two and ultimately having a profound impact on the economy.

In sum, the production boundary given by the SNA cannot meet the real needs of the current economy and accounting according to the expanded production boundary should be the future focus of national economic accounting. According to the definition of production, labor input is one of the necessary conditions for production. Therefore, the SNA has a special chapter to explore the population and labor input and other related content, to calculate the labor force in the current SNA production boundary under the standardized accounting measurement method. Production and labor input are closely related, and the sharing economy brought about by the border expansion is bound to have an impact on labor accounting. Therefore, it is necessary to explore in depth the influence of the sharing economy on labor accounting.

\section{Reconsideration of Labor Accounting}

Under the background of the sharing economy, the production boundary has been greatly expanded, which will affect the overall accounting framework of the national economy, especially the labor accounting discussed in this paper. We believe that some of the definitions in labor accounting, as well as the scope of accounting, will change the main aspects of which need to be rethought.

3.1. Employment. The scope of accounting for employment is not only a topic of concern for the International Labor
Organization but also a need for clarity in the conduct of labor accounting. The understanding of the scope of employment accounting requires that the following two points be grasped.

First, it needs to be based on the concept of population. Under the SNA and the Balance of Payments Manual (sixth edition) (BPM6), the population is defined as all permanent residents of a country in its understanding of "habitual residence" (see SNA 2008, 19.1). Such populations have the following two characteristics: (1) they have resided in the country for more than one year and (2) they are closely associated with the country and have a major center of economic interest. Second, on the basis of the definition of population, the $13^{\text {th }}$ ICLS gives a specific definition of "economic active population" as all individuals who are willing to provide labor to engage in economic activities within the scope of SNA production.

The definition of the economic active population delineates a broader scope, as can be seen from its definition, which coordinates and matches the scope criteria for employment accounting and the outputs specified under the SNA. Thus, the SNA defines employment as all persons, including employees and self-employed persons (see SNA $2008,19.19$ ), who are engaged in production activities within the scope of SNA production and are carried out under a permanent institutional unit. ICLS defines a more restrictive concept of employment, which requires people who fall into the category of employment to carry out productive activities with the aim of obtaining remuneration or benefits.

The scope of accounting for employment is limited by Division of Work forms; to meet real needs and allow for international comparisons, the $19^{\text {th }}$ ICLS has provided a more detailed division, as shown in Table 1. Under the latest form of work, the scope of employment accounting consists of two parts: (1) employment in the form of total employment and (2) employment in some other forms of work in the SNA production boundaries.

The labor forms given by ICLS and the production boundary defined by the SNA are similar, which means that for specific accounts, the concept of output is given by the SNA, while employment that is part of a form of labor will be consistent with the concept of output as defined in the SNA.

Under the sharing economy, the scope of accounting for employment has been expanded and anyone carrying out 
production activities within the general boundary of the SNA will be considered employed. At the same time, the sharing economy will also have an impact on the accounting of employees and self-employed persons. The SNA defines an employee as a person who works for a resident institution and receives remuneration from employees (see SNA 2008, 19.20), while self-employed persons are those who work for themselves and the owned enterprise is neither an independent legal entity nor an independent institutional unit in the SNA; the self-employed person may be the sole owner or co-owner of the unincorporated enterprise for whom they work and may also be a member of a cooperative producer or a contributing domestic worker (see SNA 2008, 7.30). Employment statistics in developed countries are based on employee surveys because of their high degree of economic formalization, meaning accounting for self-employed economies alone will not have a significant impact on economic analysis and policy formulation. In the context of the sharing economy, every person who expects to work can engage in either form of employment at the same time, developing the self-employment economy, which requires a more rigorous accounting method for self-employed persons, as well as a clear determination of the scope of employment and selfemployment to which employed labor belongs.

3.2. Working Time. The International Labor Organization has long been concerned about statistical issues related to working time. This is considered to be one of the main aspects that can directly measure the employment conditions and welfare of workers and can also reflect the level of social productivity, cost of institutional labor, and general quality of life in various countries. Measuring the levels and trends of various types of working time in an economy will play an important role in monitoring working and living conditions, as well as in analyzing the state of economic development.

The first ICLS had included working time in the topics under discussion. Working time, as an important tool for economic analysis and the construction of socioeconomic indicators, has been revised several times by ICLS to meet the needs of the evolving economic environment. According to ICLS, the statistical requirements for working time cover all positions and related personnel, all economic activities, and all time types.

The latest international standards are given by the $18^{\text {th }}$ ICLS, and in the resolution on working time measurement, the following seven concepts of working time are defined: (1) hours actually worked, (2) hour paid for, (3) normal hours of work, (4) contractual hours of work, (5) hours usually worked, (6) overtime hours of work, and (7) absence from work hours. Among them, most productive activities of working time go beyond the SNA production boundary but are included in the general production boundary, as shown in Table 2.

From Table 2, under the sharing economy, the statistics of the last five working hours are not affected. At the same time, since the definition of normal hours of work does not involve the self-employed economy, it does not change. However, for the definition of hour paid for, ICLS stipulates that it applies to paid positions and self-employed positions
TABLE 2: Measurement range of working time.

\begin{tabular}{lc}
\hline Type of working time & Productive activities \\
\hline $\begin{array}{l}\text { Hour paid for normal } \\
\text { hours of work }\end{array}$ & $\begin{array}{c}\text { Productive activities included } \\
\text { in the SNA production boundary }\end{array}$ \\
$\begin{array}{l}\text { Hours actually worked } \\
\text { Contractual hours of work } \\
\text { Hours usually worked }\end{array}$ & $\begin{array}{c}\text { Productive activities included } \\
\text { in the SNA production boundary }\end{array}$ \\
$\begin{array}{l}\text { Overtime hours of work } \\
\text { Absence from work hours }\end{array}$ & $\begin{array}{l}\text { Productive activities not included } \\
\text { in the SNA production boundary }\end{array}$ \\
\hline
\end{tabular}

that pay according to time units. The sharing economy incorporates a large number of household subsistence services into the SNA production boundary. The production entities of these services exist in the economy as self-employment and receive corresponding compensation. Obviously, the hour paid for will be remeasured and the scope of statistics will be expanded, which will in turn affect other accounting indicators based on pay time calculations. Additionally, since working time is obtained based on household surveys and grassroots unit surveys, and the working time of households under the sharing economy is arbitrary, this challenges how to obtain "sharing" working time in a survey. At the same time, the sharing economy requires more positions to be covered for working time statistics, so the complexity of data collection will also increase.

3.3. Labor Underutilization. In the national economic accounting, the unemployed and the employed together constitute the labor force. Countries have also made the examination of unemployment levels, and their changes are one of the main ways to monitor macroeconomic development. The SNA considers that the unemployed does not contribute to the output and therefore does not make any recommendations on this concept (see SNA 2008, 19.29). However, when moving from the concept of "employed population" to the concept of an "economic active population," it is inevitable that the "unemployed population" will be involved. As a meeting devoted to the content of labor accounting, the $13^{\text {th }}$ ICLS gave a clear definition of unemployment, that is, those who have the ability to work are not employed and are actively seeking work.

The discussion on unemployment is bound to be inseparable from the unemployment index, which is an important concept in the society. With the development of the economy and society, the information provided by the unemployment rate on government decision-making has gradually diminished; for example, in developing countries, unemployment has been decreasing annually or is even lower than in some developed countries, but low unemployment does not mean an increase in the economic welfare of these countries, nor does it mean that people's work aspirations have been largely met.

In this regard, the $18^{\text {th }}$ ICLS focused on the selection of indicators for labor underutilization, as an alternative to the inadequacy of unemployment indicators; it includes unemployment rate and, at the same time, a more comprehensive reflection of other aspects of the labor market. Three of these 


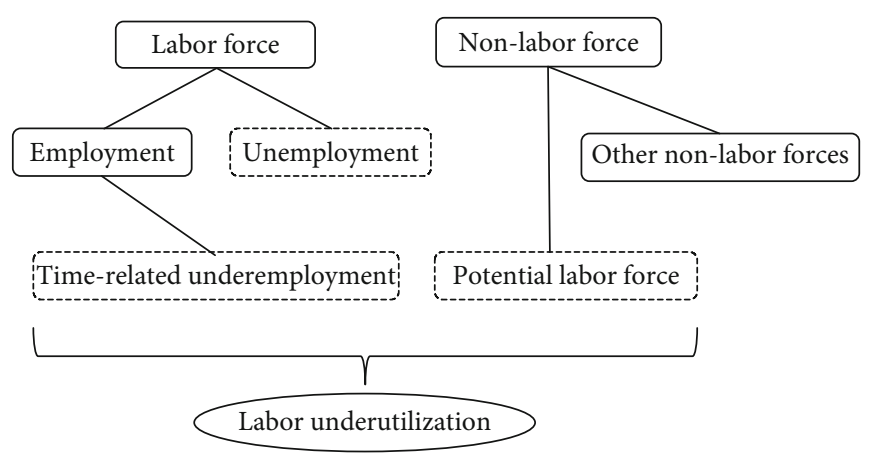

FIGURE 1: Main indicators of labor underutilization.

important indicators will be measured as (1) unemployment, (2) time-related underemployment, and (3) potential labor force. The above indicators cover most labor underutilization cases and are a comprehensive index system given by ICLS to judge the state of the labor market, as shown in Figure 1.

However, the above index system fully considers the labor demand and supply mismatch in all aspects. However, under the sharing economy, the index measure of labor underutilization will still change significantly, being mainly reflected in the following three aspects.

First, labor underutilization contains "time-related underemployment" indicators. ICLS defines this concept as an employed person who, under the condition that he/she has the will and ability to engage in other labor, does not meet the prescribed hourly threshold for working time spent in all his/her work. Under the sharing economy, the expansion of the scope of employment will lead to the opportunity and conditions for any employed person to achieve the form of sharing of labor, and his/her working time will be extended to the prescribed standards. Therefore, the measurement of the indicator in sharing economy may become meaningless.

Second, labor underutilization contains "potential labor force" indicators. They belong to the nonlabor category and consist of the following two types: (1) ability but not looking for a job and (2) inability but wanting to get a job and actively looking for it. Under the sharing economy, the second type will be excluded and, as long as there are outputs to share, that type of nonlabor will share transactions with others, a process that does not require the ability to consider, because the sharing platform will easily implement the entire process. As a result, the accounting scope of the "potential labor force" will change.

Finally, labor underutilization contains "unemployment" indicators. Under the sharing economy, as a result of the expansion of the production range, it will be possible for all individuals to carry out production activities for goods or services and sell or share these own goods and services to others. As a result, people may no longer rely on traditional external job hunting and perhaps more individuals will be engaged in "shared" employment, that is, being self-employed. As such, if the original definition is maintained, unemployment will no longer exist and the concept of unemployment may be reconsidered. In the future, unemployment refers to those who have the ability to work, are not employed, and have insufficient resources to share.

\section{Main Conclusions and Recommendations}

Labor accounting, as an important means to measure economic development and monitor changes in the labor market, will be significantly influenced by the sharing economy, meaning the connotations of existing indicators, scope of accounting, and measurement methods, among others, will change. In the context of the sharing economy, several key changes in the existing labor accounting have been discussed, and this paper draws the following main conclusions.

First, the change of labor accounting under the sharing economy lies in the expansion of production boundaries as the sharing economy changes the three reasons given under the SNA for excluding household self-sufficiency services. As such, the production boundary covers the production of most household subsistence services; labor as one of the important input elements of production, its accounting will be affected by the expansion of production boundaries.

Second, employment is one of the main aspects of labor accounting, and under the sharing economy, the scope of accounting will be extended to all institutional units carrying out production activities within the general production scope of the SNA. According to the division of the latest forms of work of ICLS, employment accounting will include employment as all "forms of employment" and in some other forms of work within the general scope of SNA production. In addition, the importance of self-employed economic employment accounting under the sharing economy is highlighted, while the determination of the boundaries of self-employment and employment may also change.

Third, as a result of the definition of "pay time," the statistical scope of the existing seven working time measures specified by ICLS will be expanded with the expansion of production boundaries under the sharing economy and accounting metrics will be remeasured. In addition, the increased difficulty of obtaining shared working time poses challenges to both survey methods and data collection.

Fourth, under the sharing economy, the accounting components and contents in labor underutilization will change as follows. First, the accounting significance of the "time-related underemployment" index will be reduced. Second, the accounting scope of the "potential labor force" will be narrowed. Finally, given the sharing economy's improvement status and future trends, "unemployment" needs to be redefined. 
As a country with the input of labor force as the main mode of production, the characteristics of China's labor resources are embodied in the abundant labor force on the one hand and in the constant change of labor force type and structure on the other hand. Mastering comprehensive and accurate labor statistics in the new environment can provide a reliable reference for the government in formulating policies. At present, the emergence of the sharing economy also tests China's labor accounting. Therefore, this paper provides some policy suggestions for China's labor accounting under the sharing economy.

4.1. Pay Attention to the Influence of Sharing Economy on Labor Accounting. The sharing economy is booming in China, and the prospects for the development of emerging environmental and economic models are unpredictable, which creates an unexpected situation for the evaluation of the future movements of labor accounting. However, because of the significant influence of the sharing economy, the impact on current labor accounting cannot be ignored. Therefore, to grasp the impact of the present sharing economy on the labor accounting of China, it is necessary to combine the connotations and characteristics of the development of this economy in China and clarify the specific process of labor accounting to lay a foundation for the embodiment of the sharing economy in accounting.

4.2. Design a Labor Accounting Index System and Perfect Data Collection Means under the Sharing Economy. We have identified the changes in the main aspects of labor accounting under the sharing economy based on the existing international standards. However, the situation of the labor market in China is complex as, in view of the current labor market accounting statistics, the established index system cannot be fully coordinated with the international one; on the other hand, it cannot fully reflect the new changes in China's current labor market development either. The characteristics of the sharing economy need to be reflected in the labor accounting indicators in the light of national realities and converge to international standards, while an index system that conforms to the national conditions and can be used for decision reference needs to be designed, which will improve the analysis framework of China's labor market. In addition, the current means of collecting labor accounting data need to be supplemented by expanding the scope and content of household surveys and surveys of grassroots units under the sharing economy to strengthen the comprehensiveness of labor information.

4.3. Strengthen the International Comparability of Labor Accounting in China under the Sharing Economy. The sharing economy is playing an increasingly prominent role in human production and life. In the context of economic globalization, the emergence of sharing economy has also led to closer exchanges among countries, which places a higher demand on strengthening international comparability in all aspects of labor accounting. However, there still exist differences between the current labor accounting system and the international standard system in China; for example, the accounting scope and caliber is not fully consistent, the design idea of the index system is not comprehensive, and the means and techniques of data collection are slightly inadequate. At the same time, the system does not fully reflect the new characteristics brought by the sharing economy in labor accounting. To this end, we need a more comprehensive sharing economy thinking model for the accounting process, design accounting standards, and feasible accounting methods suitable for the new economic environment and provide guarantees for the realization of international comparability under the sharing economy.

\section{Data Availability}

The authors solemnly declare that this study focuses on theoretical innovation, and there is no external data used to support the findings of this study during the discussion process.

\section{Conflicts of Interest}

The authors declare that they have no conflicts of interest.

\section{Acknowledgments}

It is gratefully acknowledged that this study was supported by Institute of Statistics and Applied Mathematics, Anhui University of Finance and Economics, Bengbu, China.

\section{References}

[1] M. L. Weitzman, "Increasing returns and the foundations of unemployment theory," The Econometrics Journal, vol. 92, no. 368, pp. 787-804, 1982.

[2] M. J. Peck, "Is Japan really a share economy?," Journal of Comparative Economics, vol. 10, no. 4, pp. 427-432, 1986.

[3] Y. Sano, "Changes and continued stability in Japanese HRM systems: choice in the share economy," The International Journal of Human Resource Management, vol. 4, no. 1, pp. 11-27, 1993.

[4] J. Jerger and J. Michaelis, "The fixed wage puzzle: why profit sharing is so hard to implement," Economics Letters, vol. 110, no. 2, pp. 104-106, 2011.

[5] Y. Inagaki and R. Shinkuma, "Shared-resource management using online social-relationship metric for altruistic device sharing," IEEE Access, vol. 6, pp. 23191-23201, 2018.

[6] D. Allen, "The sharing economy," Institute of Public Affairs Review: A Quarterly Review of Politics and Public Affairs, vol. 67, no. 3, p. 24, 2015.

[7] G. Zervas, D. Proserpio, and J. W. Byers, "The rise of the sharing economy: estimating the impact of Airbnb on the hotel industry," Journal of Marketing Research, vol. 54, no. 5, pp. 687-705, 2017.

[8] B. Rogers, "The social costs of Uber," in University of Chicago Law Review Dialogue, Forthcoming, p. 85, Temple University Legal Studies Research Paper No. 2015-28, 2015.

[9] R. Botsman and R. Rogers, What's Mine Is Yours: How Collaborative Consumption Is Changing the Way We Live, Harper Collins, 2010.

[10] R. Belk, "You are what you can access: sharing and collaborative consumption online," Journal of Business Research, vol. 67, no. 8, pp. 1595-1600, 2014. 
[11] W. Li and F. Lv, "The origin and reality of sharing economy," Reform, no. 12, pp. 42-51, 2015.

[12] Y. Liu and J. Xia, "Research on the theory and policy of shared economy," Economics Information, no. 4, pp. 116-125, 2016.

[13] A. Bryson and R. B. Freeman, "How does shared capitalism affect economic performance in the United Kingdom?," in Shared Capitalism at Work: Employee Ownership, Profit and Gain Sharing, and Broad-Based Stock Options, pp. 201-224, University of Chicago Press, 2010.

[14] K. Aerts, K. Kraft, and J. Lang, "Profit sharing and innovation," Industrial and Corporate Change, vol. 24, no. 6, pp. 13771392, 2015.

[15] United Nations, System of National Accounts 2008, China Statistics Press, 2012.

[16] F. Cai, Y. Du, and W. Gao, "Employment elasticity, NAIRU and macroeconomic policies," Economic Research Journal, vol. 39, no. 9, pp. 18-25, 2004.

[17] F. Cai, "Consistency of China's statistics on employment: stylized facts and implications to public policies," Chinese Journal of Population Science, no. 3, pp. 2-10, 2004.

[18] C. Shi and D. Song, "Does hidden unemployment influence China's employment growth and economic growth?," The Economist, no. 5, pp. 68-76, 2012.

[19] L. Lin and C. Wang, "The impact of labor force reduction on economy in China and its solution: based on the analysis of GTAP," Population \& Economics, vol. 1, pp. 80-87, 2014.

[20] X.-J. Chao and K. Shen, "Urban-rural income disparity, labor quality and economic growth in China," Economic Research Journal, vol. 6, pp. 30-43, 2014.

[21] L. Su and J. Chen, "A study on affect mechanism of employment quality in the new period in China: an empirical analysis based on survey data," Population \& Economics, no. 4, pp. 107-118, 2015.

[22] K. E. Long, "A study on China's social safety institution and income disparity," Public Policy Review, vol. 11, no. 1, pp. 205-230, 2015.

[23] Y. Feng and M. Zhang, "Review on labor cost in China," Population Journal, vol. 4, no. 40, pp. 103-112, 2018.

[24] D. Tang, "How vertical specialization trade influences China's employment structure?," Economic Research Journal, vol. 8, pp. 118-131, 2012.

[25] X. Chen, L. K. Cheng, K. C. Fung et al., "Domestic value added and employment generated by Chinese exports: a quantitative estimation," China Economic Review, vol. 23, no. 4, pp. 850864, 2012.

[26] Y. Wang, M. Shi, and J. Li, “The impact of environmental regulation on employment: an empirical study of the industry panel data in China," Chinese Journal of Population Science, no. 3, pp. 54-64, 2013.

[27] Y. Zhang and L. Zhang, "The formation mechanism and heterogeneity of informal employment in China-also on the applicability of the three theories," Population Journal, vol. 39, no. 2, pp. 88-99, 2017.

[28] C. Yi and C. Zhang, "Spatial distribution of unemployment and its determinants in Beijing," Chinese Journal of Population Science, vol. 6, pp. 2-11, 2015.

[29] K. Zhao, Y. Gao, and Z. Huang, "Chinese labor market equilibrium and unemployment: based on ARDL-UECM model," Statistical Research, vol. 33, no. 5, pp. 69-76, 2016. 


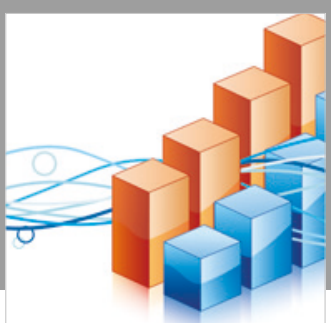

Advances in

Operations Research

\section{-n-m}
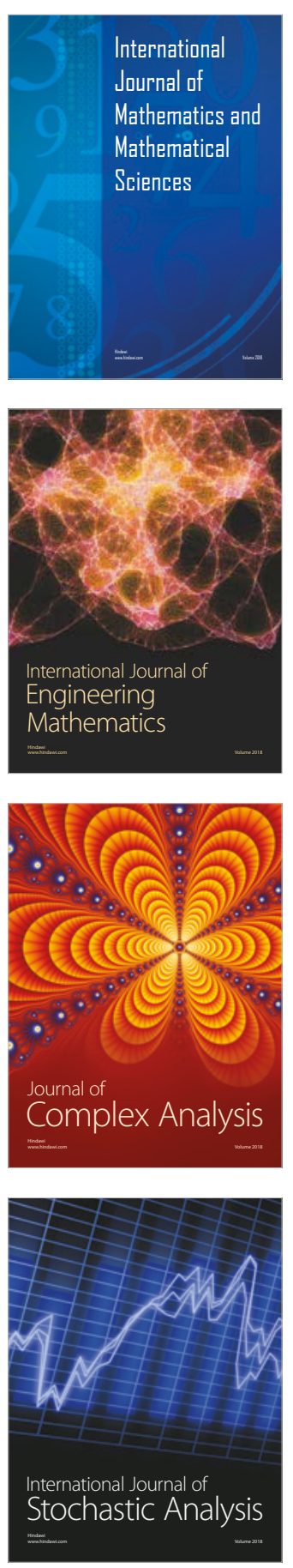
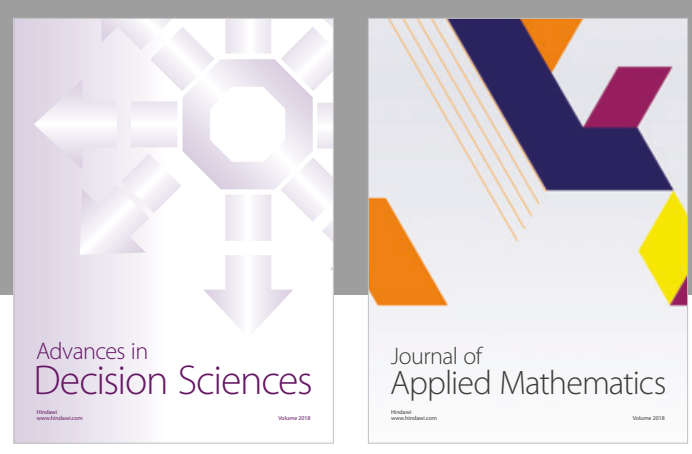

Journal of

Applied Mathematics
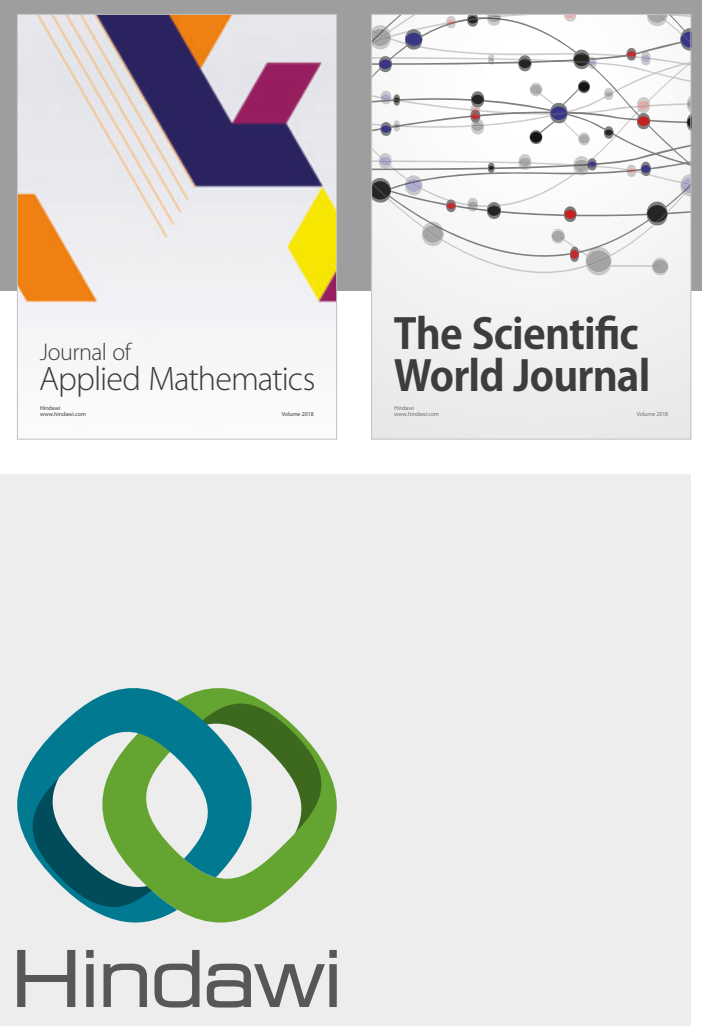

Submit your manuscripts at

www.hindawi.com

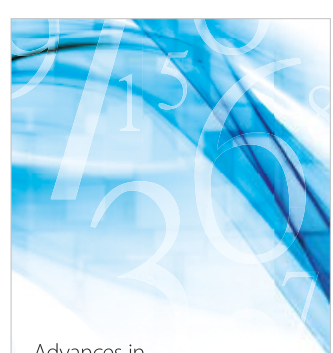

Advances in
Numerical Analysis
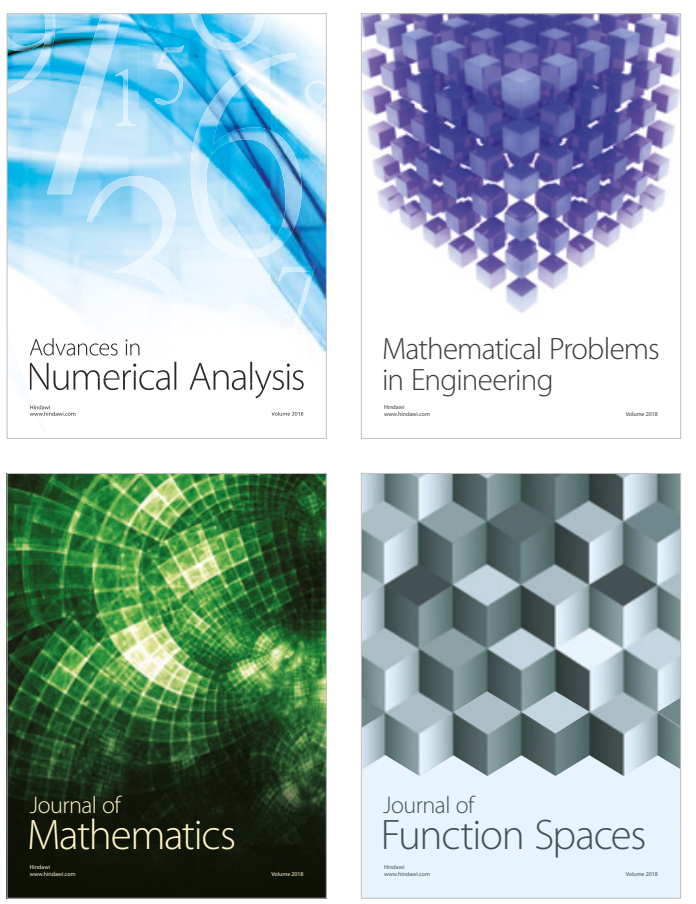

Mathematical Problems in Engineering

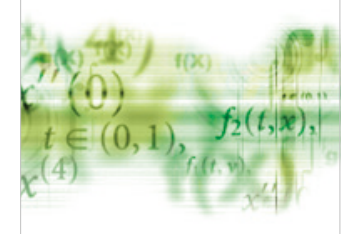

International Journal of

Differential Equations

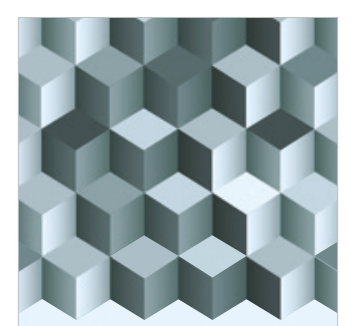

Journal of

Function Spaces

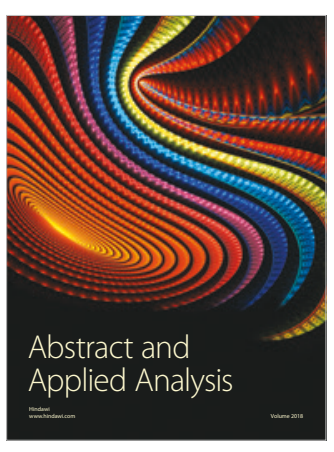

The Scientific

World Journal

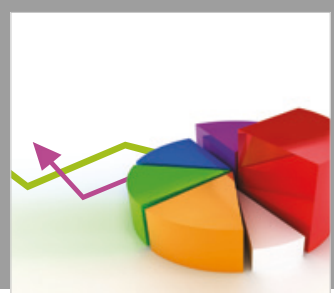

Journal of

Probability and Statistics
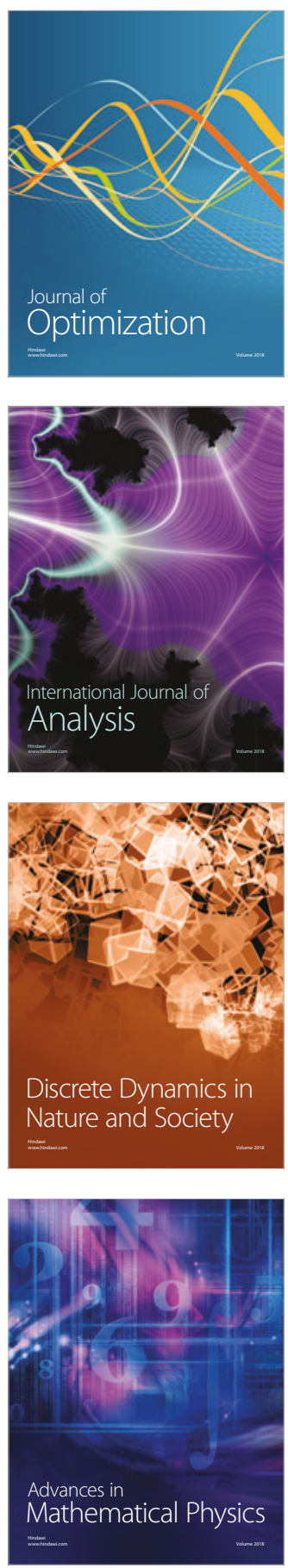